\title{
Gel in Pressurized Container
}

National Cancer Institute

\section{Source}

National Cancer Institute. Gel in Pressurized Container. NCI Thesaurus. Code C149538.

Medicinal product consisting of a gel presented in a pressurized container. 